
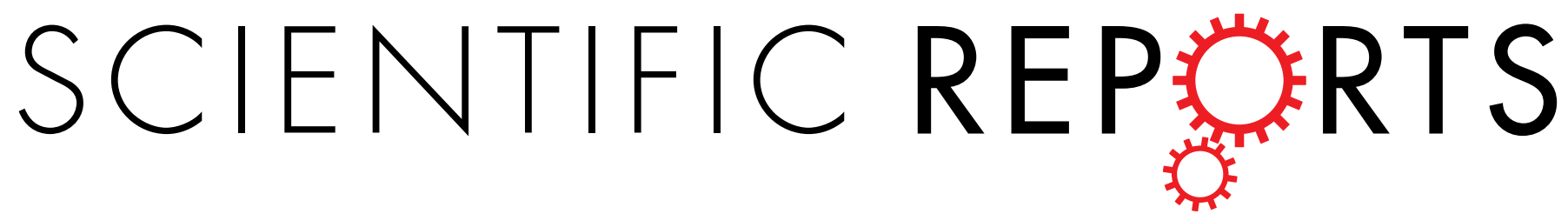

\title{
OPEN Brevibacterium from Austrian hard cheese harbor a putative histamine catabolism pathway and a plasmid for adaptation to the cheese environment
}

\author{
Justin M. Anast ${ }^{1,2}$, Monika Dzieciol $\mathbb{B}^{3}$, Dylan L. Schultz ${ }^{4}$, Martin Wagner ${ }^{3,5}$, Evelyne Mann ${ }^{3}$ \& \\ Stephan Schmitz-Esser $\mathbb{1}^{1,2}$
}

The genus Brevibacterium harbors many members important for cheese ripening. We performed realtime quantitative PCR (qPCR) to determine the abundance of Brevibacterium on rinds of Vorarlberger Bergkäse, an Austrian artisanal washed-rind hard cheese, over 160 days of ripening. Our results show that Brevibacterium are abundant on Vorarlberger Bergkäse rinds throughout the ripening time. To elucidate the impact of Brevibacterium on cheese production, we analysed the genomes of three cheese rind isolates, L261, S111, and S22. L261 belongs to Brevibacterium aurantiacum, whereas S111 and S22 represent novel species within the genus Brevibacterium based on 16S rRNA gene similarity and average nucleotide identity. Our comparative genomic analysis showed that important cheese ripening enzymes are conserved among the genus Brevibacterium. Strain S22 harbors a $22 \mathrm{~kb}$ circular plasmid which encodes putative iron and hydroxymethylpyrimidine/thiamine transporters. Histamine formation in fermented foods can cause histamine intoxication. We revealed the presence of a putative metabolic pathway for histamine degradation. Growth experiments showed that the three Brevibacterium strains can utilize histamine as the sole carbon source. The capability to utilize histamine, possibly encoded by the putative histamine degradation pathway, highlights the importance of Brevibacterium as key cheese ripening cultures beyond their contribution to cheese flavor production.

Production of cheese has been documented in many different world cultures dating back more than 7500 years ${ }^{1,2}$. The production of cheese is dependent on complex interactions of diverse microorganisms dispersed throughout the cheese ingredients and the production facility. Particularly in long-ripened cheeses, the microorganisms on the cheese surface contribute significantly to flavor production. These cheese rind microbial communities can either be inoculated artificially with surface-ripening cultures during the manufacturing process, be present in starting ingredients, or establish themselves through inoculation from the microbial communities of the ripening cellar environment during the ripening process ${ }^{3-6}$. Many genera of the bacterial phylum Actinobacteria, including - among others - the genus Brevibacterium, are important for flavor production during cheese ripening ${ }^{5,7-9}$. The contribution of Brevibacterium towards cheese production has been under investigation for some time, showing that it can break down lipids and proteins (i.e. casein) with the use of extracellular proteases and lipases ${ }^{9,10}$. Many Brevibacterium isolates also have the ability to modify sulfur-containing amino acids to produce volatile sulfur compounds which are important for flavor development ${ }^{11-13}$. Brevibacterium strains are thus often used as surface-ripening cultures in many different cheese types ${ }^{8}$. Understanding the functional potential of cheese bacteria is essential in the combined effort with cheese producers to shorten ripening times, reduce spoilage, better control cheese aroma, and increase food safety.

${ }^{1}$ Interdepartmental Microbiology Graduate Program lowa State University, Ames, IA, USA. ${ }^{2}$ Department of Animal Science, lowa State University, Ames, IA, USA. ${ }^{3}$ Institute for Milk Hygiene, University of Veterinary Medicine Vienna, Vienna, Austria. ${ }^{4}$ Interdepartmetal Microbiology Undergraduate Program, lowa State University, Ames, IA, USA. ${ }^{5}$ Austrian Competence Center for Feed and Food Quality, Safety and Innovation (FFoOSI), Technopark C, 3430, Tulln, Austria. Correspondence and requests for materials should be addressed to S.S.-E. (email: sse@iastate.edu) 
The taxonomy of the genus Brevibacterium is under reorganization with Brevibacterium genomes varying greatly in both size and functional content ${ }^{7,14,15}$. It should be noted that the genus Brevibacterium also contains opportunistic pathogens and other biotechnologically important species ${ }^{16-19}$. Cheese-associated subtypes of Brevibacterium can be found in several species of the genus, suggesting that adaptation to cheese environments might have been acquired independently through horizontal gene transfer (HGT) events ${ }^{15,20}$. Two recent studies have analyzed the genetic content of Brevibacterium focusing on their putative genetic functions in cheese production. The first provided evidence for the prevalence of HGT in cheese-associated Actinobacteria in general and the existence of highly conserved islands denoted iron uptake/siderophore transport island (RUSTI), which are presumed to be involved in iron uptake ${ }^{20}$. Iron acquisition capabilities are a key fitness advantage of cheese bacteria because of the scarcity of free iron in cheese and milk ${ }^{20,21}$. The second study analyzed 23 Brevibacterium isolate genomes, 12 of which were isolated from cheese, and found many putative genes involved in iron acquisition and bacteriocin production. Notably, they found a $96 \mathrm{kbp}$ insertion element in a number of Brevibacterium genomes containing lanthipeptide bacteriocin genes, which they designated Brevibacterium Lanthipeptide Island (BreLI) ${ }^{15}$. These BreLI islands thus potentially provide a competitive advantage to their host strains against other bacteria.

A number of studies have shown that some Brevibacterium strains such as B. aurantiacum and B. linens, even if intentionally inoculated on surface-ripened cheeses, do not establish themselves during ripening ${ }^{22-28}$. Studies that assess abundance of Brevibacterium on the rind during cheese ripening are limited to a number of (semi-quantitative) 16S rRNA gene amplicon sequencing studies ${ }^{3,28-30}$; however, quantitative PCR approaches focusing on Brevibacterium are, to the best of our knowledge, confined to one study ${ }^{31}$. The latter study used reverse transcriptase qPCR to determine the abundance of Brevibacterium and other cheese rind bacteria and yeasts on French smear-ripened cheeses targeting ribosomal RNAs or different protein coding genes.

Histamine is a biogenic amine (BA) that is involved with the immune, cardiovascular, and gastrointestinal systems in mammals. However, in bacteria, its production is often associated with survival mechanisms responding to acidic environments ${ }^{32-34}$. Histamine can be produced in high concentration by bacteria during food fermentation ${ }^{35}$ with concentrations reaching up to $400 \mathrm{mg} / \mathrm{kg}$ depending on the type of cheese $\mathrm{e}^{36-38}$. Consumption of histamine can lead to histamine intoxication; characterized by diarrhea, asthma, swelling, rash, hives and other allergic-like reaction conditions ${ }^{34,39}$. Long-ripened cheese is among the most commonly associated sources of dietary-acquired BAs, surpassed only by fish ${ }^{37,40,41}$. Histamine intoxication can be mitigated by preventing histamine formation or by degrading histamine in foods. One way to reduce histamine levels in cheese may thus be to add histamine-degrading bacteria to the cheeses during cheese production and ripening.

Vorarlberger Bergkäse (VB) is a long-ripened artisanal hard cheese derived from raw milk of cows grazing alpine pastures in the western region of Austria known as Vorarlberg. VB cheese wheels are regularly washed with brine or surface treated with dry salt. The ripening time may span from three to 18 months, during this time a rind consisting of bacteria and fungi will form on the cheeses. No external surface-ripening cultures are added. Our group has previously characterized the microbial community composition of VB using 16S and 18S rRNA gene cloning and sequencing ${ }^{42}$. Different Brevibacterium phylotypes have been characterized to be abundant on the rind and in production facilities of $\mathrm{VB}^{6}$. This study aimed to characterize the abundance of Brevibacterium on VB cheese rinds using qPCR and to analyze the contribution of Brevibacterium to cheese ripening based on draft genome sequences for three Brevibacterium isolates from VB: L261, S22, and S111. Their genetic potential in regards to cheese ripening was compared to other cheese-associated Brevibacterium strains. We hypothesize that the VB Brevibacterium isolates are habituated for the competitive environment of the cheese rind throughout the ripening time and contribute to the texture, color, and aroma of VB.

\section{Results and Discussion}

qPCR results. The abundance of Brevibacterium on VB cheese rinds during ripening was determined through qPCR analysis. Overall, a higher abundance of Brevibacterium was found in plant B compared to plant A. At day 0, Brevibacterium was present in higher bacterial cell equivalents (BCEs) in plant B than in A (Median, 4.21e +07 and 1.46e +06 , respectively) (Fig. 1, Tables S1 and S2). Brevibacterium BCEs from plant A were increasing significantly during the first 30 days ( 4.2 fold increase from 0 to 30 days, $\mathrm{p}<0.01 ; 2.8$ fold increase from 14 to 30 days, $\mathrm{p}<0.01$ ), and remained relatively constant during the rest of the ripening time. Brevibacterium BCEs in plant $\mathrm{B}$ changed significantly when comparing day 0 to 14 (1.6 fold increase, $\mathrm{p}<0.05$ ), day 14 to 30 (7.5 fold- decrease, $\mathrm{P}<0.05)$ and day 90 to 160 (4.6 fold decrease, $\mathrm{p}<0.01$ ).

Our qPCR results show that the genus Brevibacterium is found in high BCEs on the surface of VB already at day 0 of processing and remained abundant throughout the observed ripening time of 160 days. Some studies have reported that Brevibacterium strains, even if inoculated on the rinds for ripening, do not establish themselves on cheese rinds ${ }^{22-28}$. This is in contrast to the notion that Brevibacterium are late-successional taxa on cheese surfaces $^{3,28}$. Our previous study showed that Brevibacterium clones are abundant on VB cheese rinds and one of the Brevibacterium Operational Taxonomic Units (OTUs) increased significantly during cheese ripening $^{42}$. It has been suggested that the abundance of Brevibacterium on cheese rinds is highly strain-dependent or dependent on the co-occurring cheese microbiota such as fungi. Growth of Brevibacterium on cheese rinds is stimulated by Geotrichum candidum ${ }^{43}$ and inhibited by Penicillium ${ }^{3}$. Brevibacterium is abundant on VB cheese rinds already at the first day of production; this suggests that Brevibacterium might originate in high numbers from the raw milk used for production of VB. In line with this, Brevibacterium have often been found in raw milk $^{44}$. Raw milk-associated Brevibacterium seem to be the most likely possible source of transmission as a recent study from our group indicated that Brevibacterium is the second most abundant clone from both VB rinds and ripening cellar environments ${ }^{6}$. A possible inoculation of VB rinds with Brevibacterium in such high numbers as reported here from the production environment in such short time (i.e. at the day of production) seems to be unlikely. These results do not prove a source of transmission, the origin of the cheese rind Brevibacterium strains needs to be verified experimentally in future studies. 

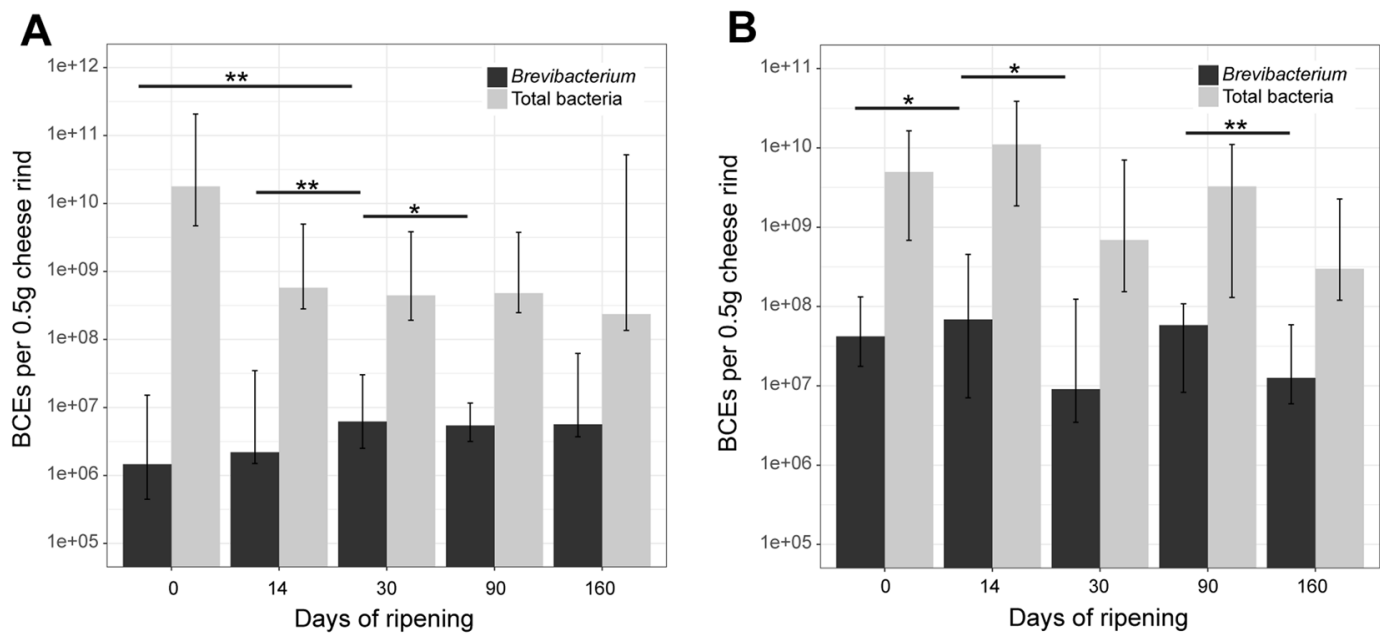

Figure 1. Abundance of Brevibacterium on cheese rinds during ripening of Vorarlberger Bergkäse in two different cheese production plants determined by qPCR. Bacterial cell equivalents (BCE) per $0.5 \mathrm{~g}$ cheese rind during ripening in two different cheese production facilities are shown. Graphs show median and interquartile ranges for the 20 samples from each plant [(A): plant A, and (B): plant B] for each analyzed day of ripening $(0$, 14, 30, 90 and 160 days). Statistically significant differences of Brevibacterium BCEs are highlighted by asterisks, with *indicating $\mathrm{p}<0.05$ and $* *$ indicating $\mathrm{p}<0.01$. Numerical BCE values are shown in Table S1, p-values are shown in Table S2.

Isolation of bacteria from VB rinds. To obtain cheese rind bacteria isolates for functional characterization such as genome sequencing, we performed a cultivation approach on VB cheese rinds yielding a total number of 143 isolates, see ${ }^{45}$ for details. Out of these isolates, 10 were identified as Brevibacterium. Based on a 99\% $16 \mathrm{~S}$ rRNA gene sequence similarity threshold, these isolates belonged to three OTUs (data not shown). From each of these OTUs, one strain was selected for whole genome sequencing. Brevibacterium S22 and L261 were isolated from one month old cheese rinds, Brevibacterium S111 was isolated from six months old cheese samples. $16 \mathrm{~S}$ rRNA gene-based phylogenetic analysis of the three new isolates from this study with other Brevibacterium strains revealed that all three strains clearly clustered within the genus Brevibacterium (Fig. 2). Brevibacterium L261 clustered together with B. aurantiacum, whereas S22 and S111 clustered together with the B. linens/B. siliguriense/B. iodiunum group recently postulated by ${ }^{15}$. Brevibacterium L261 shows yellow-orange pigmentation and Brevibacterium $\mathrm{S} 111$ showed beige pigmentation, whereas Brevibacterium $\mathrm{S} 22$ colonies are white.

Similarity of VB cheese rind isolates to VB cheese rind and production environment clones. The near full-length 16S rRNA gene sequences of S22, S111 and L261, which were isolated in 2014, were compared to $16 \mathrm{~S}$ rRNA gene clone sequences from our previous studies that analyzed VB rinds and production environments sampled in 2012 from the same cheese production plants using BLASTn ${ }^{6,42}$. L261 showed 98.8\% identity to OTU2 from $^{42}$ and $99.6 \%$ identity OTU3 from ${ }^{6}$ and S111 showed $99.8 \%$ identity to OTU19 from ${ }^{42}$. S22 showed less than $98 \%$ identity to Brevibacterium OTUs from ${ }^{42}$ and $99.8 \%$ identity to OTU18 from ${ }^{6}$. These results suggest that different Brevibacterium strains or species can be found in the VB cheese rind communities and also in the VB production environment for over a time period of several years, although it should be noted that, based on 16S rRNA similarity alone, a differentiation of strains is not possible; for this, approaches with higher taxonomic resolution such as Pulsed-Field Gel Electrophoresis (PFGE) or Multi Locus Sequence Typing (MLST) would be needed.

Genome sequencing and analysis of Brevibacterium from VB rinds. Illumina MiSeq sequencing and assembly yielded between 70 and 100 contigs for each strain with an average coverage of $160 \times$ for S22, 255× for S111, and $275 \times$ for L261. Brevibacterium L261 had an assembly size of $4.48 \mathrm{Mbp}$ within 100 contigs, the assembly size for L261 is larger than those of other B. aurantiacum isolates (Table 1), which is consistent with the described variability of genome sizes in the genus Brevibacterium ${ }^{15}$. The genomic GC content of L261 (62.8\%) was highly similar to other B. aurantiacum isolates (62.6 to $62.8 \%$ ). L261 average nucleotide identity (ANI) and $16 \mathrm{~S}$ rRNA gene sequence similarity were above the threshold of species demarcations (ANI >95\%, 16S rRNA gene $>99 \%)^{46,47}$ to sequenced B. aurantiacum genomes (B. aurantiacum SMQ-1335, B. aurantiacum ATCC 9174, and B. aurantiacum ATCC 9175), suggesting that L261 belongs to the species B. aurantiacum. Also, Pham et al. ${ }^{15}$ considered Brevibacterium genomes belong to the same species with $16 \mathrm{~S}$ rRNA gene similarity $>98 \%$ and ANI $>95 \%$. Similarly, also tetranucleotide correlation analyses revealed that these four B. aurantiacum genomes had tetra correlation values higher than 0.999 , which is also indicative of belonging to the same species (Table S3). B. linens has been split into four different species: B. linens, B. aurantiacum, B. antiquum and B. permense ${ }^{14}$ which was confirmed by recent genome-based phylogenetic analyse ${ }^{15}$. Brevibacterium S22 and S111 reads were assembled into 72 and 70 contigs with assembly sizes of 4.51 and $4.04 \mathrm{Mbp}$, respectively. ANI $(<86 \%)$ and $16 \mathrm{~S}$ rRNA gene similarities $(<98.6 \%)$ of S22 and S111 were below the threshold of species demarcation when compared to other Brevibacterium type strains analyzed, thus S22 and S111 probably represent novel species in the genus 


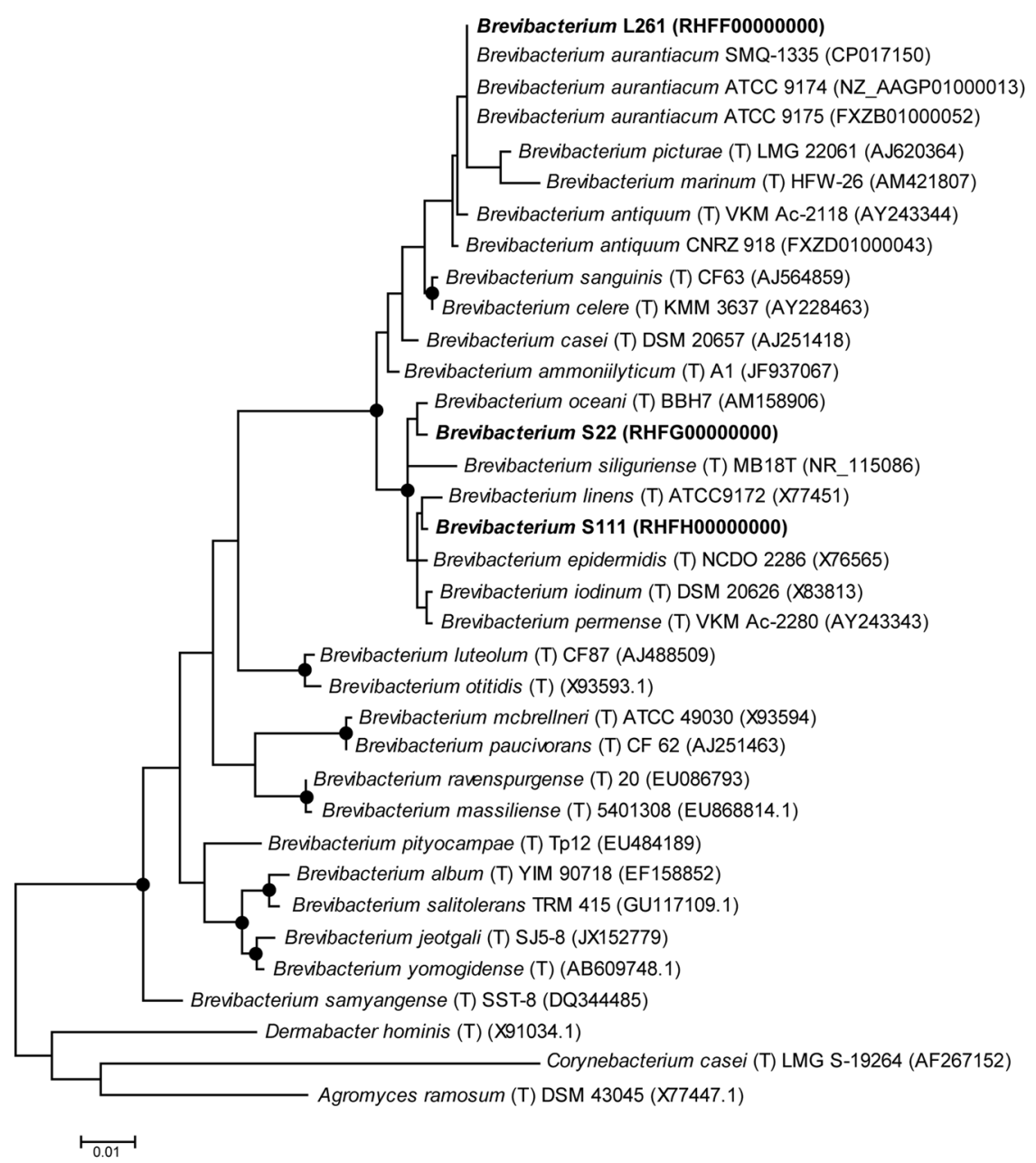

Figure 2. Phylogenetic relationships of Brevibacterium strains based on $16 \mathrm{~S}$ rRNA gene sequences. The evolutionary history was inferred by using the Maximum Likelihood method based on the Tamura-Nei model. The tree with the highest log likelihood $(-4232.79)$ is shown. The tree is drawn to scale, with branch lengths measured in the number of substitutions per site. The analysis involved 35 nucleotide sequences. All positions containing gaps and missing data were eliminated. There were a total of 1127 positions in the final dataset. Evolutionary analyses were conducted in MEGA7 ${ }^{85}$. Isolates obtained in this study are highlighted in bold. Type strains are indicated by "(T)", GenBank accession numbers are shown in parentheses. Black dots indicate Maximum Likelihood, Neighbor-Joining and Maximum Parsimony bootstrap values higher than 85 (1000x resampling).

Brevibacterium. Similarly, also the tetranucelotide correlation analyses values for S22 and S111 were below the cutoff $(<0.996)$ for species demarcation (Table S3). Unambiguous and formal description of S22 and S111 as novel species of the genus Brevibacterium would require additional experimental work which was outside the scope of this study.

Functional potential for cheese ripening. To characterize the functional potential of Brevibacterium isolates for cheese production, we analyzed the annotated genomes for enzymes characterized in previous studies to be important for cheese ripening. Sulfur-containing amino acids have been described as important precursors for volatile sulfur compounds responsible for flavor of cheeses ${ }^{13,48}$. Genomes of Brevibacterium L261, S111, and S22 harbor three copies of a putative methionine aminopeptidase (EC 3.4.11.18) and encode one homolog of the methionine gamma-lyase (EC 4.4.1.11, MGL), which shows high amino acid identity (94\%, $80 \%$, and $78 \%$, respectively) to the characterized MGLs from B. aurantiacum ATCC 9175 and ATCC $9174^{11,49}$. The locus_tags for the homologs of the cheese enzymes discussed in this section in Brevibacterium L261, S111, and S22 are listed in Table S4. MGLs can produce methanethiol from methionine, which in turn is converted to various volatile sulfur containing compounds important for aroma of the cheese ${ }^{13,48}$. Proline and glutamate are found in high abundance in casein ${ }^{50-52}$. Isolates S22, S111, and L261 can metabolize proline through one proline iminopeptidase (EC 3.4.11.5) and one Xaa-Pro aminopeptidase (EC 3.4.11.9). In addition, L261, S111, and S22 harbor homologs with high amino acid identity $(\geq 68 \%$ ) to the cell wall-associated protease characterized from B. aurantiacum ATCC $9174^{53}$. Furthermore, different aminopeptidases have been described in Brevibacterium to be important 


\begin{tabular}{|c|c|c|c|c|c|c|c|c|c|c|}
\hline & $\begin{array}{l}\text { B. aurantiacum } \\
\text { L261 }\end{array}$ & $\begin{array}{l}\text { Brevibacterium } \\
\text { S111 }\end{array}$ & $\begin{array}{l}\text { Brevibacterium } \\
\text { S22 }\end{array}$ & $\begin{array}{l}\text { B. aurantiacum } \\
\text { SMQ-1335 }\end{array}$ & $\begin{array}{l}\text { B. aurantiacum } \\
\text { ATCC } 9174\end{array}$ & $\begin{array}{l}\text { B. aurantiacum } \\
\text { ATCC } 9175\end{array}$ & $\begin{array}{l}\text { B. antiquum } \\
\text { CNRZ } 918\end{array}$ & $\begin{array}{l}\text { B. casei } \\
\text { CIP } 102111\end{array}$ & $\begin{array}{l}\text { B. linens } \\
\text { ATCC } 9172\end{array}$ & $\begin{array}{l}\text { B. iodinum } \\
\text { ATCC } 49514\end{array}$ \\
\hline Assembly size (Mbp) & 4.481 & 4.043 & 4.507 & 4.209 & 4.366 & 4.147 & 3.748 & 3.840 & 3.959 & 3.535 \\
\hline Reference & 42 & 42 & 42 & 88 & $\begin{array}{l}\text { Bioproject } \\
\text { PRJNA405 }\end{array}$ & 15 & 15 & 15 & 15 & 15 \\
\hline Source & VB, Austria & VB, Austria & VB, Austria & Cheese & $\begin{array}{l}\text { Romadour } \\
\text { cheese, Germany }\end{array}$ & $\begin{array}{l}\text { Camembert } \\
\text { cheese }\end{array}$ & $\begin{array}{l}\text { Beaufort } \\
\text { cheese, } \\
\text { France }\end{array}$ & $\begin{array}{l}\text { Cheddar } \\
\text { cheese }\end{array}$ & $\begin{array}{l}\text { Harzer } \\
\text { cheese, } \\
\text { Germany }\end{array}$ & Milk \\
\hline No of contigs & 100 & 70 & 72 & 1 & 76 & 70 & 49 & 24 & 80 & 65 \\
\hline $\begin{array}{l}\text { 16S rRNA similarity } \\
\text { to L261 }\end{array}$ & & $96.7 \%$ & $96.4 \%$ & $99.9 \%$ & $99.3 \%$ & $99.7 \%$ & $99.0 \%$ & $97.3 \%$ & $97.0 \%$ & $96.3 \%$ \\
\hline $\begin{array}{l}\text { 16S rRNA similarity } \\
\text { to S111 }\end{array}$ & $96.7 \%$ & & $97.8 \%$ & $96.7 \%$ & $96.4 \%$ & $96.7 \%$ & $96.8 \%$ & $97.5 \%$ & $98.6 \%$ & $98.4 \%$ \\
\hline $\begin{array}{l}\text { 16S rRNA similarity } \\
\text { to } \$ 22\end{array}$ & $96.4 \%$ & $97.8 \%$ & & $96.7 \%$ & $96.7 \%$ & $96.3 \%$ & $96.9 \%$ & $97.2 \%$ & $98.1 \%$ & $97.4 \%$ \\
\hline $\begin{array}{l}\text { ANI* to L261 (\%) } \\
\text { [coverage] }\end{array}$ & & $78.89[55.25]$ & $78.82[55.43]$ & $96.02[76.23]$ & $95.73[78.68]$ & 96.12 [75.99] & $86.2[62.11]$ & $77.21[48.56]$ & $78.97[54.61]$ & 78.62 [50.94] \\
\hline $\begin{array}{l}\text { ANI* to S111 (\%) } \\
\text { [coverage] }\end{array}$ & $79.26[60.75]$ & & 84.04 [68.39] & $78.6[57.57]$ & $78.71[59.2]$ & 78.59 [58.07] & $77.9[55.17]$ & $77.77[51.23]$ & $83.82[63.9]$ & 83.47 [60.47] \\
\hline $\begin{array}{l}\text { ANI* to S22 (\%) } \\
\text { [coverage] }\end{array}$ & $78.69[55.13]$ & 83.91 [61.88] & & $78.18[52.71]$ & $78.54[54.06]$ & 78.38 [53.39] & $77.86[48.87]$ & $77.38[45.81]$ & $86.44[60.41]$ & 86.65 [58.53] \\
\hline GC content & $62.8 \%$ & $65.0 \%$ & $64.1 \%$ & $62.6 \%$ & $62.8 \%$ & $62.7 \%$ & $62.7 \%$ & $68.0 \%$ & $64.7 \%$ & $64.5 \%$ \\
\hline
\end{tabular}

Table 1. Overview on Brevibacterium strains included in this study. *ANI was calculated with the Blast algorithm using the JSpeciesWS Webserver.

\begin{tabular}{|l|l|l|l|}
\hline $\begin{array}{l}\text { Proteolytic activity } \\
\text { (skim milk agar plates) }\end{array}$ & $\begin{array}{l}\text { Halo size } \\
\text { day } 7\end{array}$ & $\begin{array}{l}\text { Halo size } \\
\text { day } \mathbf{1 4}\end{array}$ & $\begin{array}{l}\text { Halo size } \\
\text { day } \mathbf{2 1}\end{array}$ \\
\hline Brevibacterium S22 & small & small & large \\
\hline Brevibacterium S111 & small & large & large \\
\hline B. aurantiacum L261 & small & medium & large \\
\hline $\begin{array}{l}\text { Lipolytic activity } \\
\text { (spirit blue agar plates) }\end{array}$ & medium & medium & large \\
\hline Brevibacterium S22 & small & large & large \\
\hline Brevibacterium S111 & small & medium & large \\
\hline B. aurantiacum L261 &
\end{tabular}

Table 2. Proteolytic and lipolytic activity of Brevibacterium isolates S22, L261, and S111.

for cheese ripening ${ }^{9,54,55}$. L261, S22 and S111 contained homologs with high similarity (92 to $100 \%$ amino acid identity) to the $\mathrm{N}$-terminal sequence of aminopeptidase II identified in B. linens SR3 by ${ }^{55}$. L261, S22 and S111 also contain homologs with high similarity (63\% amino acid identity) to the N-terminal sequence of an aminopeptidase characterized in B. aurantiacum ATCC 9174 by $^{56}$. Glutamate can be metabolized by employing three copies of glutamate dehydrogenase (EC 1.4.1.2). Aminotransferases are important in the transformation of amino acids into aroma compounds during cheese production ${ }^{12,48,57}$. Isolates S22, S111, and L261 harbor both putative aromatic and branched-chain aminotransferases (EC 2.6.1.57 and 2.6.1.42). Lipolytic enzymes such as esterases are important in cheese ripening and esterase activity has been described in Brevibacterium before ${ }^{9,10}$. Rattray and Fox ${ }^{58}$ have purified an intracellular esterase from B. aurantiacum ATCC 9174; L261, S22, and S111 contain homologs to the N-terminal sequence of the purified esterase sharing 84 to $94 \%$ amino acid identity. The L261, S22, S111, and all other genomes analyzed, harbor a cluster of genes possibly involved in phenylacetate degradation. Phenylacetate has been described to be responsible for off-flavor in Cheddar ${ }^{59}$, but also key for flavor production in Swiss-type cheeses ${ }^{60}$.

Protease and lipase activities of Brevibacterium isolates. The Brevibacterium isolates S22, S111, and L261 were analyzed for their protease and lipase activity by qualitatively scoring halo formation on skim milk and Spirit Blue agars, respectively. Protease and lipase activity was observed in all three isolates. By comparing the relative size of halos between strains it was determined that S111 showed the highest activity when assessed for proteolytic and lipolytic activity after 14 days; after 21 days, the halo sizes were similar for all three strains (Table 2).

Differences between L261, S22, and S111. While many described and identified genes important for cheese ripening are conserved between different Brevibacterium strains, we also identified a number of different features between the three VB isolates. Isolate S22 (but not L261 and S111) contains an ureABCDFG gene cluster for degradation of urea; some Brevibacterium strains have been described to be able to degrade urea ${ }^{14}$. The presence of a urease gene cluster could enable Brevibacterium to degrade urea to ammonia and thereby increase the $\mathrm{pH}$ on the cheese rind. Homologs of this cluster were also identified in the cheese isolates B. linens ATCC 9172 
and B. casei CIP 102111. The growth of Brevibacterium on cheese is stimulated by vitamin production of yeasts and fungi ${ }^{9}$, we found that strain L261 encodes all genes necessary for biotin production (bioABCDFH), while S22 and S111 encode only an incomplete biotin biosynthesis pathway. All strains analyzed in this study also encode a BioMNY putative biotin transporter. The presence of a complete biotin synthesis pathway might provide advantages to L261 during growth on cheese rinds.

Brevibacterium S22 encodes a novel 22 kb plasmid. A putative plasmid contig was identified in Brevibacterium S22, it has a size of $22.4 \mathrm{kbp}$, a GC content of $64.4 \%$ and encodes 25 predicted genes, two of them show high amino acid identity to the RepA and RepB proteins (between 74 and 63\%, respectively) from the pLIM, pRBL1 and pBLA8 plasmids from $B$. linens ${ }^{61-63}$. The coverage of the plasmid contig was $1763 \times$, which is 11 -fold higher than the average coverage of the chromosomal contigs $(160 \times)$ suggesting that the S22 plasmid is a medium-copy number plasmid. Agarose gel electrophoresis and restriction enzyme digest confirmed the size and presence of a plasmid, which we named pBS22 (Fig. S1). PCR assays targeting the ends of the plasmid contig revealed PCR products of approximately $500 \mathrm{bp}$ and demonstrated that pBS22 is a circular plasmid (data not shown). Homologs to a hydroxylmethyl pyrimidine (HMP)/thiamine ABC transporter described in Bacillus subtilis (YkoCDE) ${ }^{64}$, an iron import system (IrtAB) functionally characterized in Mycobacterium tuberculosis ${ }^{65,66}$, and a multi-drug resistance pump (Stp), shown to increase tolerance to spectinomycin and tetracycline characterized also in Mycobacterium tuberculosis ${ }^{67}$, were identified on pBS22 (Fig. S2). Some of the other predicted proteins on the plasmid were annotated as transcriptional regulators or transposases, and a few could not be assigned with a putative function based on sequence analysis. Most of the plasmid genes show highest similarity to bacteria other than Brevibacterium. The putative IrtAB iron transporters show highest amino acid identity ( 73 and $77 \%)$ to the cheese isolate Gulosibacter sp $10^{68}$ and Agrococcus casei LMG22410 68 (62 and 67\% amino acid identity); the amino acid identity to Brevibacterium homologs is below $47 \%$. The putative YkoCDE transporters show also highest similarity to homologs in Gulosibacter sp 10 (72 to 78\% amino acid identity) and various non cheese-derived Actinobacteria (63\% to $67 \%$ amino acid identity); the amino acid identity to Brevibacterium homologs is below $43 \%$. Plasmids such as pBL33 (7.5 kb), pLIM (7.6 kb), pBL100 $(7.7 \mathrm{~kb})$, or pRBL1 (8 kb) have been identified in some Brevibacterium isolates, but so far, the function of these plasmids remains unknown ${ }^{9,61-63,69,70}$. These plasmids belong to the family of theta-replicating ColE-related plasmids ${ }^{61-63}$. Phylogenetic analyses of plasmid RepA protein sequences revealed that the pBS22 RepA protein clustered consistently together, but more distant and more deeply with other RepA proteins from the genus Brevibacterium (Fig. S3). pBS22 lacks homologs of the ORFIII proteins found in many Brevibacterium plasmids (Table S5), but encodes putative MobAC plasmid mobilization proteins which do not show similarity to other Brevibacterium proteins. Recently, a $89 \mathrm{~kb}$ linear plasmid, pAP13, was identified in a Brevibacterium isolate from feces ${ }^{71,72}$ but also for this plasmid, no putative function is currently known. pAP13 shows no similarity to pBS22 determined by BlastP analyses. The identification of pBS22, which is putatively involved in iron and vitamin uptake and might thus provide an adaptive advantage on cheese rinds, is thus the first description of a non-cryptic plasmid in Brevibacterium. An increased knowledge about the distribution and potential function of Brevibacterium plasmids as performed in this study is a prerequisite for identifying plasmids and - in the long term - to be able to develop a genetic system for Brevibacterium. This is of particular relevance given the importance of Brevibacterium as cheese ripening strains and that transformation of Brevibacterium has been described only in a few strains and transformation efficiency is highly strain dependent ${ }^{62,73}$.

Possible plasmid content in other Brevibacterium strains. When using the pLIM RepAB and the replication-associated ORFIII proteins as query for BlastP searches against other Brevibacterium genomes, we identified highly similar homologs with more than $95 \%, 68 \%$, and $89 \%$ amino acid identity (RepA, RepB, ORFIII, respectively) in a number of Brevibacterium strains including B. aurantiacum ATCC 9174 (Table S5). Interestingly, the homologs in B. aurantiacum ATCC 9174 are located on one contig with a size of $8.7 \mathrm{~kb}$, which is highly similar to the size of pBL33 which has been purified from B. aurantiacum ATCC 9174 and analyzed by restriction enzyme analyses to be $7.5 \mathrm{~kb}$ previously ${ }^{69}$. It is thus likely that this B. aurantiacum ATCC 9174 contig represents the cryptic plasmid pBL33. Based on the similarity of RepAB and ORFIII proteins, and the clustering of RepA proteins (Fig. S3) and the presence of these homologs on contigs with sizes ranging from 5.2 to $9 \mathrm{~kb}$, we speculate that small cryptic plasmids with replication proteins highly similar to pLIM, pRBL1, and pBLA8 are found in a higher number of Brevibacterium strains than previously anticipated. It should be noted that these sequence analyses do not prove whether these contigs do actually represent complete or partial plasmids.

Comparative genomic analysis of previously described Brevibacterium genomic islands and bacteriocin loci. Iron is a limiting resource for cheese microorganisms ${ }^{5,21}$. The recently described RUSTI and BreLI islands ${ }^{15,20}$ are absent in Brevibacterium isolates S22, S111, and L261. However, homologs of smaller previously described bacteriocin gene clusters were found: L261, S22 and S111 encode a putative Linocin-M18 bacteriocin. Linocin-M18 was isolated from Brevibacterium linens M18 and inhibits the growth of many gram-positive bacteria, including species of the genus Listeria ${ }^{74}$ and is found in many Brevibacterium strains and coryneform bacteria ${ }^{15}$. L261 encodes homologs of a lactococcin 972-related bacteriocin and of a linear azol(in)e-containing peptide gene cluster recently identified by ${ }^{15}$.

Histamine metabolism. Sequence analysis of isolates S22, S111, and L261 revealed homologs to a recently described histamine catabolism pathway in Pseudomonas putida ${ }^{75}$ (Table 3, Fig. S4). Isolates S22, S111, and L261 have homologs with high similarity (amino acid identity $\geq 40 \%$ ) to HinADFGHIL proteins and lower, but still high, similarity (amino acid identity 32 to $36 \%$ ) to HinC and HinK. In addition, we found highly similar homologs ( $\geq 52 \%$ amino acid identity) of a functionally characterized histamine oxidase (E.C. 1.4.3.22) from 


\begin{tabular}{|l|l|l|l|}
\hline $\begin{array}{l}\text { P. putida protein (GenBank } \\
\text { accession number) }\end{array}$ & $\begin{array}{l}\text { Brevibacterium L261 } \\
\text { Amino acid identity (\%), [coverage \%], } \\
\text { NCBI GenBank locus_tag }\end{array}$ & $\begin{array}{l}\text { Brevibacterium S111 } \\
\text { Amino acid identity (\%), [coverage \%], } \\
\text { NCBI GenBank locus_tag }\end{array}$ & $\begin{array}{l}\text { Brevibacterium S22 } \\
\text { Amino acid identity (\%), [coverage \%], } \\
\text { NCBI GenBank locus_tag }\end{array}$ \\
\hline HinA permease (AWA45220) & 50 [98], EB834_11790 & 51 [98], EB836_13825 & 50 [98], EB835_06785 \\
\hline $\begin{array}{l}\text { HinD EC 1.2.1.3 } \\
\text { aldehyde dehydrogenase } \\
\text { (AWA45224) }\end{array}$ & 50 [98], EB834_10860 & 50 [99], EB836_11485 & 50 [99], EB835_13590 \\
\hline $\begin{array}{l}\text { HinF EC 1.14.13.5 } \\
\text { FAD-monooxygenase } \\
\text { (AWA45229) }\end{array}$ & 63 [92], EB834_10890 & 60 [94], EB836_11515 & 61 [92], EB835_13560 \\
\hline $\begin{array}{l}\text { HinG EC 3.5.1.8 amidase } \\
\text { (AWA45228) }\end{array}$ & 43 [98], EB834_09805 & $42[98]$, EB836_03650 & 40 [97], EB835_02985 \\
\hline HinH amidase (AWA45227) & 48 [100], EB834_10875 & 50 [100], EB836_11500 & 48 [100], EB835_13575 \\
\hline $\begin{array}{l}\text { HinI aspartate ammonia-lyase } \\
\text { EC 4.3.1.1 } \\
\text { (AWA45233) }\end{array}$ & 56 [98], EB834_10895 & $56[96]$, EB836_11520 & 54 [97], EB835_13555 \\
\hline $\begin{array}{l}\text { HinL enamine deaminase } \\
\text { (AWA45230) }\end{array}$ & 65 [98], EB834_10880 & 61 [99], EB836_11505 & 64 [98], EB835_13570 \\
\hline
\end{tabular}

Table 3. Homologs of Pseudomonas putida histamine catabolism enzymes in Brevibacterium L261, S111, S22.

Arthrobacter globiformis ${ }^{76}$ in S22, L261, and S111. This histamine oxidase could fulfil the function of HinC, for which only a homolog with lower similarity has been found using the Pseudomonas putida HinC as query. HinC from Pseudomonas putida is a histamine-deaminase/histamine-pyruvate aminotransferase that catalyzes the oxidation of histamine to imidazole acetaldehyde. Similar to HinC, histamine oxidase also catalyzes the conversion of histamine to imidazole acetaldehyde. In the Brevibacterium strains S22, L261 and S111, homologs of both HinC and the Arthrobacter histamine oxidase might have the potential to perform the initial step of histamine degradation. Some Pseudomonas putida histamine genes homologs were absent in the Brevibacterium strains analyzed here. HinE is an aldehyde dehydrogenase that complements HinD in the oxidation of imidazole acetaldehyde to imidazole-4-acetate. Histamine degradation was not hindered in hinE deletion mutants ${ }^{75}$, thus it is a nonessential gene for histamine degradation. We found no homologs of HinB and HinJ, which are transcriptional regulators; the absence of clear homologs of transcriptional regulators might be explained by different transcriptional regulation of histamine degradation genes between Pseudomonas putida and Brevibacterium, which belong to different phyla.

The other Brevibacterium genomes analyzed in this study encode homologs of only some of the genes in the Pseudomonas putida histamine degradation pathway described by ${ }^{75}$ (Table S6, Fig. S4). Based on this, we speculate that the histamine degradation potential may be absent in the other Brevibacterium genomes analyzed here. It should be noted that some of the other Brevibacterium strains analyzed here contain homologs of the histamine oxidase from Arthrobacter globiformis, they could therefore perform the initial step of histamine degradation and might use other, yet unknown, pathways for complete histamine degradation. However, proof of the presence or absence of histamine degradation potential would need to be verified experimentally in those strains in future studies.

To provide experimental evidence that Brevibacterium L261, S111, and S22 can degrade histamine, we performed growth experiments in minimal medium (MM) with or without $10 \mathrm{mM}$ histamine as the sole carbon source. The growth curves revealed that all three strains are capable to utilize histamine and grow in MM supplemented with $10 \mathrm{mM}$ histamine (Fig. 3). Growth occurred to a maximal optical density (OD) of 1.1 to 1.6 (depending on the strain) after reaching those maximal ODs, the cultures switched to stationary phase. No growth was observed for the strains cultured in MM without added histamine. These results show that Brevibacterium L261, S111, and S22 can utilize histamine. However, to determine if the genes in the putative histamine degradation pathway are responsible for histamine degradation, needs to be verified in future experiments. Our results are in line with previous reports that have described histamine degradation for Brevibacterium strains ${ }^{77,78}$; however, the molecular pathway responsible for histamine degradation in Brevibacterium has not been identified until now. Here, we provide evidence for histamine degradation and the presence of a putative histamine degradation pathway in Brevibacterium strains L261, S22, and S111 which could enable them to reduce levels of histamine in hard cheeses.

Furthermore, all genomes in this study were then analyzed for their potential ability to produce histamine by a histidine decarboxylase (E.C. 4.1.1.22) similar to other cheese bacteria ${ }^{37}$. No homologs of histidine decarboxylases were identified, suggesting that all strains are incapable of histamine synthesis.

\section{Conclusion}

Here we report the draft genome sequences of Brevibacterium isolates from Austrian hard cheese rinds. One of the isolates (L261) belonged to B. aurantiacum, and two of the isolates (S22 and S111) most likely represent novel Brevibacterium species. Our qPCR results show that Brevibacterium strains are abundant members of the VB cheese rind communities throughout 160 days of ripening. The genomes of Brevibacterium strains S22 and S111 provide further evidence for the diversity of the genus Brevibacterium in general and of cheese-associated Brevibacterium in particular. Our results show that many important enzymes for cheese ripening are conserved among cheese-associated Brevibacterium. Brevibacterium S22 harbors a plasmid which might provide adaptation advantages on cheese rinds by encoded putative iron and thiamine import proteins. We reveal evidence for the presence of a potential metabolic pathway responsible for histamine degradation which is found in cheese-associated Brevibacterium strains L261, S22, and S111. Growth experiments revealed that these isolates are able to degrade histamine which underscores the importance of Brevibacterium strains as cheese ripening cultures. 


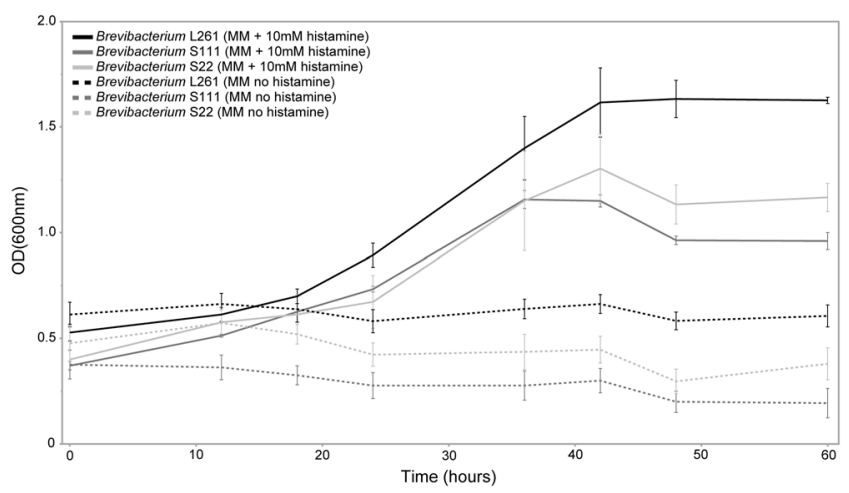

Figure 3. Growth of Brevibacterium strains S22, S111, and L261 in minimal medium (MM) with or without $10 \mathrm{mM}$ histamine as sole carbon source. Growth was determined using optical density measurements at $600 \mathrm{~nm}$ $\left(\mathrm{OD}_{600}\right)$. Values represent mean values $\pm \mathrm{SEM}$.

\section{Methods}

This study used the same samples for qPCR and cultivation as described recently in detail $\mathrm{in}^{45}$.

Cheese rind sampling. Cheese rind samples were obtained from VB cheese wheels in ripening cellars of two different cheese production operations (abbreviated A and B) located in Vorarlberg, Austria. Samples were taken in March 2014 from 20 cheese wheel rinds directly after production (day 0) and at 14, 30, 90 and 160 days of ripening time.

Isolation and identification of cheese rind bacteria. The cultivation of cheese rind bacteria followed the procedures described in ${ }^{45}$. Briefly, two grams of each sample were homogenized in $20 \mathrm{~mL}$ of sterile Ringer solution using a Stomacher 400 blender. Aliquots of $100 \mu \mathrm{L}$ were diluted in sterile Ringer Solution and plated on modified ATCC medium 1097 [casamino acids $7.5 \mathrm{~g}^{-\mathrm{L}}$; proteose peptone $5.0 \mathrm{~g}^{-\mathrm{L}}$; yeast extract $1.0 \mathrm{~g}^{-\mathrm{L}}$, sodium citrate $3.0 \mathrm{~g}^{-\mathrm{L}}, \mathrm{MgSO}_{4} \times 7 \mathrm{H}_{2} \mathrm{O} 20.0 \mathrm{~g}^{-\mathrm{L}}, \mathrm{K}_{2} \mathrm{HPO}_{4} 0.5 \mathrm{~g}^{-\mathrm{L}}, \mathrm{Fe}\left(\mathrm{NH}_{4}\right)_{2}\left(\mathrm{SO}_{4}\right)_{2} \times 6 \mathrm{H}_{2} \mathrm{O}$, vancomycin $5 \mathrm{mg}^{-\mathrm{L}}$, crystal violet $5 \mathrm{mg}^{-\mathrm{L}}, 8 \%(\mathrm{wt} / \mathrm{vol}) \mathrm{NaCl}$ ] under aerobic conditions at $37^{\circ} \mathrm{C}$. The main focus of our cultivation approach was to enrich for Gram-negative bacteria ${ }^{45}$; thus, vancomycin and crystal violet were used as described in $^{79}$. Nevertheless, also many Gram-positive isolates were retrieved in spite of the vancomycin and crystal violet added to the original growth media (data not shown). DNA was isolated with the NucleoSpin Tissue DNA Extraction Kit (Macherey-Nagel) using the manufacturer's recommended specifications. The extracted DNA was used for $16 \mathrm{~S}$ rRNA gene PCR amplification using primers $27 \mathrm{~F}$ (5'-AGA GTT TGA TCM TGG CTC AG-3') and $1492 \mathrm{R}$ $\left(5^{\prime}\right.$-GGY TAC CTT GTT ACG ACT T- $\left.3^{\prime}\right)$ applying the following amplification conditions: initial denaturation at $95^{\circ} \mathrm{C}$ for 5 minutes, followed by 30 cycles at $94^{\circ} \mathrm{C}$ for 40 seconds, at $52^{\circ} \mathrm{C}$ for 40 seconds, at $72{ }^{\circ} \mathrm{C}$ for 60 seconds and final extension at $72^{\circ} \mathrm{C}$ for 7 minutes. Purification of PCR amplicons was done using the GeneJet PCR Purification Kit (Thermo Fisher Scientific) and sequenced using a Sanger platform to produce near full-coverage of the $16 \mathrm{~S}$ rRNA gene sequences.

Genome sequencing, assembly, and analysis of Brevibacterium isolates. DNA was isolated by employing the Qiagen Genomic-tip columns (20/G) using the manufacturer's recommended specifications. An Illumina MiSeq platform (Microsynth, Balgach, Switzerland) was used for genome sequencing with paired-end-sequencing chemistry and 300 base pair (bp) read length. One Illumina Nextera XT library with a 1 $\mathrm{kbp}$ insert size was prepared for each genome. The reads for each strain were assembled with SPAdes ${ }^{80}$. The draft genome sequences of the Brevibacterium isolates were annotated and analyzed using PATRIC, www.patricbrc.org ${ }^{81}$. Annotations of genes of interest were confirmed using NCBI BLASTp, Uniprot ${ }^{82}$, and Pfam webservers ${ }^{83}$. The proteomes of isolates L261, S22, and S111 were compared with other Brevibacterium strains using PATRIC Blastp and proteome comparison tools. The average nucleotide identity (ANI) and tetranucleotide correlation analyses between isolates were determined using the JSpeciesWS online server ${ }^{84}$. Phylogenetic relationships of Brevibacterium strains based on 16S rRNA were calculated with MEGA 7 using maximum likelihood, neighbor joining and maximum parsimony with $1000 \times$ bootstrapping $^{85}$. For the maximum likelihood tree shown in Fig. 2, initial tree(s) for the heuristic search were obtained automatically by applying Neighbor-Join and BioNJ algorithms to a matrix of pairwise distances estimated using the Maximum Composite Likelihood (MCL) approach and then selecting the topology with superior log likelihood value.

Accession numbers. This Whole Genome Shotgun project was deposited at DDBJ/ENA/GenBank under the accession XXXX00000000. The version described in this paper is version XXXX01000000. The genomes of L261, S22, and S111 have been deposited under the accession numbers RHFF00000000, RHFG00000000, and RHFH00000000 respectively. Raw reads were submitted to the NCBI Sequence Read Archive (SRA) with the Bioproject accession number PRJNA498327.

qPCR to determine the abundance of Brevibacterium on cheese rinds. DNA extraction. Ten grams of cheese rind samples were homogenized in $30 \mathrm{~mL}$ of sterile Ringer Solution and centrifuged to produce a 
$250 \mathrm{mg}$ pellet $^{45}$. Genomic DNA was isolated from the pellets by utilizing the PowerSoil DNA Isolation kit (MoBio) following the producers guidelines. Aliquots $(250 \mu \mathrm{L})$ were pooled in duplicate and DNA concentrations were determined with a Qubit ${ }^{\circledR} 2.0$ Fluorometer (Thermo Fisher Scientific).

qPCR analysis of 16S rRNA genes. To assess differences in abundance between cellars from two dairy production plants and alterations in the absolute abundance in respect to ripening time, the amount of total bacteria and of Brevibacterium were quantified using qPCR. The data for $16 \mathrm{~S}$ rRNA gene PCR analysis of total bacterial numbers in VB cheese rind samples was taken from Schmitz-Esser, $2018^{45}$. We used previously designed primers to amplify a $125 \mathrm{bp}$ target region of the $16 \mathrm{~S}$ rRNA genes of the genus Brevibacterium, 16S_Ba838-856 (F) (5'-GTA CGG TCG CAA GGC TAA A-3') and 16S_Ba921-904 (R) (5'-TCC AGA ACG GTC TGG TGT-3' $)^{31}$.

Negative controls without template were included in each qPCR reaction. The specificity of the amplicons was verified by DNA sequencing of the PCR products (LGC Genomics, Berlin, Germany), showing 99 to $100 \%$ identity to the 16S rRNA gene sequences of their respective target organisms. qPCR conditions and primers were optimized to obtain high PCR amplification efficiency of the target included in the qPCR assay as described in ${ }^{86}$ (Table S7). Each optimized qPCR reaction was run in duplicate with a final volume of $25 \mu \mathrm{L}$, using MicroAmp $0.2 \mathrm{~mL}$ optical tubes sealed with MicroAmp optical 8-cap strips (Applied Biosystems). Single amplification reactions for Brevibacterium qPCRs consisted of $11.95 \mu \mathrm{L}$ diethylpyrocarbonate (DEPC)-treated water, $2.5 \mu \mathrm{L} 10 \times$ buffer, $1.75 \mu \mathrm{L} 3.5 \mathrm{mM} \mathrm{MgCl}_{2}, 0.75 \mu \mathrm{L} 300 \mathrm{nM}$ of each primer, $1 \mu \mathrm{L} 3.3 \mathrm{mM}$ SYTO9 (Invitrogen), $1 \mu \mathrm{L} 200 \mathrm{mM}$ of each dNTP, $0.3 \mu \mathrm{L} 1.5$ U of Platinum ${ }^{\circledR}$ Taq DNA polymerase (Thermo Fisher Scientific) and $5 \mu \mathrm{L}$ template (genomic DNA). The quantification of DNA was performed in Mx3000P ${ }^{\mathrm{TM}} \mathrm{qPCR}$ system (Stratagene) (software v.4.10) after initial denaturation at $94^{\circ} \mathrm{C}$ for two min, followed by 45 cycles of $94^{\circ} \mathrm{C}$ for $30 \mathrm{~s}, 60^{\circ} \mathrm{C}$ for one min. To determine the specificity of the amplifications, dissociation curves after each reaction were recorded and carried out at $95^{\circ} \mathrm{C}$ for one min, followed by complete annealing at $50^{\circ} \mathrm{C}$ for $30 \mathrm{~s}$, and a gradual increasing temperature up to $95^{\circ} \mathrm{C}$. Post-run melting curves were checked for the presence of multiple peaks due to primer-dimers or nonspecific amplification. Additionally, to check for the presence of non-specific products and size of the amplicons, aliquots of qPCR products were analyzed by agarose gel electrophoresis.

DNA isolated from Brevibacterium L261 was used as the DNA qPCR standard to determine the absolute abundance of Brevibacterium, expressed as the bacterial cell equivalents (BCE) per $0.5 \mathrm{~g}$ cheese rind. The DNA concentration was determined fluorimetrically using a Qubit ${ }^{\circledR} 2.0$ Fluorometer. When based on the mean molecular weight of 23 Brevibacterium genomes ${ }^{15}$ and three sequenced isolates described in this study $(3,879,418 \mathrm{bp})$, $1 \mathrm{ng}$ DNA equals $2.39 \times 10^{5}$ copies of the entire genomes. The $16 \mathrm{~S}$ rRNA gene copy numbers (mean: three copies for Brevibacterium ${ }^{15}$ ) were taken into account when extrapolating BCE per $0.5 \mathrm{~g}$ rind cheese from the qPCR.

The qPCR data (BCE per $0.5 \mathrm{~g}$ cheese rind) were analysed and compared using $\mathrm{R}$ (version 3.2.5, psych package 1.6.12). The dataset was divided into 10 different subsets based on the location (cheese production facility A, B) and days of ripening $(0,14,30,90$ and 160). Because the Shapiro-Wilk test did show normal distribution for only one of the 10 subsets, all subsets were described by Median and interquartile ranges (IQR). Furthermore, the Wilcoxon Signed-Rank test was used to determine statistical differences (at a significance level $\leq 0.05$ ) between subsets with the same location based on days of ripening. A p-value $\leq 0.05$ was considered statistically significant. Due to the fact, that no relationship between the two cheese facilities (A and B) were found (Kendall's Rank correlation Tau-B), observed qPCR data from two facilities were analysed separately.

Purification, and analysis of the Brevibacterium S22 plasmid. A putative plasmid was identified in Brevibacterium S22 through sequence analysis and was designated pBS22. To confirm the presence of this plasmid, Brevibacterium S22 was cultivated overnight in Brain Heart Infusion broth (BD Biosciences) with 3\% (wt/ vol) added $\mathrm{NaCl}$ at $37^{\circ} \mathrm{C}$ and shaking at $200 \mathrm{rpm}$. Plasmid DNA was purified using the GeneJET Plasmid Minprep Kit (Thermo Scientific). Plasmid DNA was linearized with the restriction enzyme HindIII (Thermo Scientific) and loaded on an agarose gel. Primers pBS22Fwd (5'-TCA GTG AGC AAC GTG AGG-3') and pBS22Rev (5'-TAT GCC AGA CAT GTC GGG-3') were used to elucidate if pBS22 is a circular plasmid. PCR conditions were as follows: initial denaturation at $94^{\circ} \mathrm{C}$ for 3 minutes, followed by 35 cycles at $94^{\circ} \mathrm{C}$ for 30 seconds, at $52^{\circ} \mathrm{C}$ for 30 seconds, at $72^{\circ} \mathrm{C}$ for 60 seconds and a final extension at $72{ }^{\circ} \mathrm{C}$ for 7 minutes. The PCR amplicons were purified using the PureLink ${ }^{\mathrm{TM}}$ Quick PCR Purification Kit (Invitrogen by Thermo Fisher Scientific) and sequenced using a Sanger platform to complete the plasmid sequence.

Proteolysis and lipolysis screening. Brevibacterium isolates L261, S22, and S111 were screened qualitatively for lipolytic and proteolytic properties. Cultures were grown overnight in Brain Heart Infusion broth (BD Biosciences) with $3 \%$ (wt/vol) added $\mathrm{NaCl}$ and incubated at $30^{\circ} \mathrm{C}$ and shaking at $210 \mathrm{rpm}$. Cultures were diluted to an $\mathrm{OD}_{600}$ of $0.2 .10 \mu \mathrm{L}$ of each diluted culture was transferred on the center of a skim milk agar plate [5\% (wt/ vol) skim milk (BD Biosciences), $1 \%$ (wt/vol) yeast extract (BD Biosciences), and $2 \%$ (wt/vol) agar (Thermo Fisher Scientific)] and on a Spirit Blue Agar plate (BD Biosciences) [2\% (wt/vol) agar, 1\% (wt/vol) tryptone, $0.5 \%$ $(\mathrm{wt} / \mathrm{vol})$ of yeast extract, $0.015 \%$ (wt/vol) spirit blue, $3 \%$ (vol/vol) lipase reagent] in duplicate to assess proteolytic and lipolytic activities following recently published procedures ${ }^{10}$. Plates were incubated at $20^{\circ} \mathrm{C}$. Observations occurred once every seven days for a total of 21 days. Presence and size of clear haloes on the agar plates indicate proteolytic and lipolytic activity.

Growth of Brevibacterium in minimal medium with histamine. To test if the Brevibacterium isolates S22, S111, and L261 can utilize histamine, we determined growth curves in a defined MM containing histamine as sole carbon source ${ }^{75,87}$. The $\mathrm{MM}$ consisted of $\left(\mathrm{gL}^{-1}\right)$ : $\mathrm{KH}_{2} \mathrm{PO}_{4}(13.6),\left(\mathrm{NH}_{4}\right)_{2} \mathrm{SO}_{4}(2.0), \mathrm{MgSO}_{4} * 7 \mathrm{H}_{2} \mathrm{O}(0.25)$, $\mathrm{FeSO}_{4} * 7 \mathrm{H}_{2} \mathrm{O}(0.0005)$, biotin (0.0003), thiamine hydrochloride (0.0012), and calcium panthotenate $(0.00015)$. The $\mathrm{pH}$ was adjusted to 8 . This medium was used with or without addition of $10 \mathrm{mM}$ histamine as carbon source. 
Test tubes containing $5 \mathrm{ml} \mathrm{MM}$ were inoculated with the one loop (approx. $10 \mu \mathrm{l}$ ) bacterial colony grown on marine broth -tryptic soy agar plates consisting of $\left(\mathrm{gL}^{-1}\right)$ : Marine broth (Becton Dickinson, 40.1), tryptic soy broth (Becton Dickinson, 13.3), $\mathrm{NaCl}(30.0)$, agar (10.0). The $\mathrm{pH}$ was adjusted to 7.5. Incubations were carried out in a shaker $(200 \mathrm{rpm})$ at $30^{\circ} \mathrm{C}$ and optical density (OD) at $600 \mathrm{~nm}$ was determined.

\section{References}

1. Salque, M. et al. Earliest evidence for cheese making in the sixth millennium BC in northern Europe. Nature 493, 522-525, https:// doi.org/10.1038/nature11698 (2013).

2. McClure, S. B. et al. Fatty acid specific $\delta^{13} \mathrm{C}$ values reveal earliest Mediterranean cheese production 7,200 years ago. PLOS ONE 13, e0202807, https://doi.org/10.1371/journal.pone.0202807 (2018).

3. Wolfe, B. E., Button, J. E., Santarelli, M. \& Dutton, R. J. Cheese rind communities provide tractable systems for in situ and in vitro studies of microbial diversity. Cell 158, 422-433, https://doi.org/10.1016/j.cell.2014.05.041 (2014).

4. Irlinger, F., Layec, S., Helinck, S. \& Dugat-Bony, E. Cheese rind microbial communities: diversity, composition and origin. FEMS Microbiol Lett 362, 1-11, https://doi.org/10.1093/femsle/fnu015 (2014).

5. Monnet, C., Landaud, S., Bonnarme, P. \& Swennen, D. Growth and adaptation of microorganisms on the cheese surface. FEMS Microbiol Lett 362, 1-9, https://doi.org/10.1093/femsle/fnu025 (2015).

6. Quijada, N. M. et al. Autochthonous facility-specific microbiota dominates washed-rind Austrian hard cheese surfaces and its production environment. Int J Food Microbiol 267, 54-61, https://doi.org/10.1016/j.ijfoodmicro.2017.12.025 (2018).

7. Bora, N., Dodd, C. \& Desmasures, N. Diversity, dynamics and functional role of Actinomycetes on European smear ripened cheeses (Springer, 2015).

8. Bockelmann, W., Willems, K. P., Neve, H. \& Heller, K. H. Cultures for the ripening of smear cheeses. Int Dairy J 15, 719-732, https:// doi.org/10.1016/j.idairyj.2004.08.022 (2005).

9. Rattray, F. P. \& Fox, P. F. Aspects of enzymology and biochemical properties of Brevibacterium linens relevant to cheese ripening: a review. J Dairy Sci 82, 891-909, https://doi.org/10.3168/jds.S0022-0302(99)75308-7 (1999).

10. Ozturkoglu-Budak, S., Wiebenga, A., Bron, P. A. \& de Vries, R. P. Protease and lipase activities of fungal and bacterial strains derived from an artisanal raw ewe's milk cheese. Int J Food Microbiol 237, 17-27, https://doi.org/10.1016/j.ijfoodmicro.2016.08.007 (2016).

11. Amarita, F. et al. Identification and functional analysis of the gene encoding methionine-gamma-lyase in Brevibacterium linens. Appl Environ Microbiol 70, 7348-7354, https://doi.org/10.1128/AEM.70.12.7348-7354.2004 (2004).

12. Yvon, M., Chambellon, E., Bolotin, A. \& Roudot-Algaron, F. Characterization and role of the branched-chain aminotransferase (BcaT) isolated from Lactococcus lactis subsp cremoris NCDO 763. Appl Environ Microbiol 66, 571-577 (2000).

13. Bonnarme, P., Psoni, L. \& Spinnler, H. E. Diversity of L-methionine catabolism pathways in cheese-ripening bacteria. Appl Environ Microbiol 66, 5514-5517 (2000).

14. Gavrish, E. et al. Three new species of Brevibacteria-Brevibacterium antiquum sp nov., Brevibacterium aurantiacum sp nov. and Brevibacterium permense sp nov. Microbiology 73, 176-183 (2004).

15. Pham, N. P. et al. Comparative genomic analysis of Brevibacterium strains: insights into key genetic determinants involved in adaptation to the cheese habitat. BMC Genomics 18, 955, https://doi.org/10.1186/s12864-017-4322-1 (2017).

16. Wauters, G. et al. Identification of a novel Brevibacterium species isolated from humans and description of Brevibacterium sanguinis sp nov. J Clin Microbiol 42, 2829-2832, https://doi.org/10.1128/jcm.42.6.2829-2832.2004 (2004).

17. Funke, G., von Graevenitz, A., Clarridge, J. E. 3rd \& Bernard, K. A. Clinical microbiology of coryneform bacteria. Clin Microbiol Rev 10, 125-159 (1997).

18. Gruner, E. et al. Human infections caused by Brevibacterium casei, formerly CDC groups B-1 and B-3. J Clin Microbiol 32, 1511-1518 (1994).

19. Onraedt, A., Soetaert, W. \& Vandamme, E. Industrial importance of the genus Brevibacterium. Biotechnol Lett 27, 527-533, https:// doi.org/10.1007/s10529-005-2878-3 (2005).

20. Bonham, K. S., Wolfe, B. E. \& Dutton, R. J. Extensive horizontal gene transfer in cheese-associated bacteria. Elife 6, https://doi. org/10.7554/eLife.22144 (2017).

21. Monnet, C., Back, A. \& Irlinger, F. Growth of aerobic ripening bacteria at the cheese surface is limited by the availability of iron. Appl Environ Microbiol 78, 3185-3192, https://doi.org/10.1128/AEM.00085-12 (2012).

22. Brennan, N. M. et al. Biodiversity of the bacterial flora on the surface of a smear cheese. Appl Environ Microbiol 68, 820-830, https:// doi.org/10.1128/aem.68.2.820-830.2002 (2002).

23. Mounier, J. et al. Surface microflora of four smear-ripened cheeses. Appl Environ Microbiol 71, 6489-6500 (2005).

24. Rea, M. C. et al. Stability of the biodiversity of the surface consortia of Gubbeen, a red-smear cheese. J Dairy Sci 90, 2200-2210, https://doi.org/10.3168/jds.2006-377 (2007).

25. Goerges, S. et al. Commercial ripening starter microorganisms inoculated into cheese milk do not successfully establish themselves in the resident microbial ripening consortia of a south german red smear cheese. Appl Environ Microbiol 74, 2210-2217, https://doi. org/10.1128/aem.01663-07 (2008).

26. Gori, K., Ryssel, M., Arneborg, N. \& Jespersen, L. Isolation and identification of the microbiota of Danish farmhouse and industrially produced surface-ripened cheeses. Microb Ecol 65, 602-615, https://doi.org/10.1007/s00248-012-0138-3 (2013).

27. Monnet, C. et al. Investigation of the activity of the microorganisms in a reblochon-style cheese by metatranscriptomic analysis. Front Microbiol 7, https://doi.org/10.3389/fmicb.2016.00536 (2016).

28. Bertuzzi, A. S. et al. Omics-based insights into flavor development and microbial succession within surface-ripened cheese. mSystems 3, https://doi.org/10.1128/mSystems.00211-17 (2018).

29. Ceugniez, A. et al. Use of a metagenetic approach to monitor the bacterial microbiota of "Tomme d'Orchies" cheese during the ripening process. Int J Food Microbiol 247, 65-69, https://doi.org/10.1016/j.ijfoodmicro.2016.10.034 (2017).

30. Quigley, L. et al. High-throughput sequencing for detection of subpopulations of bacteria not previously associated with artisanal cheeses. Appl Environ Microbiol 78, 5717-5723, https://doi.org/10.1128/AEM.00918-12 (2012).

31. Monnet, C. et al. Quantification of yeast and bacterial gene transcripts in retail cheeses by reverse transcription-quantitative PCR. Appl Environ Microbiol 79, 469-477, https://doi.org/10.1128/AEM.02360-12 (2013).

32. Linares, D. M., Martin, M. C., Ladero, V., Alvarez, M. A. \& Fernandez, M. Biogenic amines in dairy products. Crit Rev Food Sci Nutr 51, 691-703, https://doi.org/10.1080/10408398.2011.582813 (2011).

33. Spano, G. et al. Biogenic amines in fermented foods. Eur J Clin Nutr 64(Suppl 3), S95-100, https://doi.org/10.1038/ejcn.2010.218 (2010).

34. Rai, K. P., Pradhan, H. R., Sharma, B. K. \& Rijal, S. K. Histamine in foods: Its safety and human health implications. J Food Sci Technol Nepal 8, 1-11 (2013).

35. Burdychova, R. \& Komprda, T. Biogenic amine-forming microbial communities in cheese. FEMS Microbiol Lett 276, 149-155, https://doi.org/10.1111/j.1574-6968.2007.00922.x (2007).

36. EFSA Panel on Biological Hazards (BIOHAZ). Scientific Opinion on risk based control of biogenic amine formation in fermented foods. EFSA Journal 9, 2393, https://doi.org/10.2903/j.efsa.2011.2393 (2011). 
37. O'Sullivan, D. J. et al. High-throughput DNA sequencing to survey bacterial histidine and tyrosine decarboxylases in raw milk cheeses. BMC Microbiol 15, 266, https://doi.org/10.1186/s12866-015-0596-0 (2015).

38. Mayer, H. K., Fiechter, G. \& Fischer, E. A new ultra-pressure liquid chromatography method for the determination of biogenic amines in cheese. J Chromatogr A 1217, 3251-3257, https://doi.org/10.1016/j.chroma.2009.09.027 (2010).

39. Maintz, L. \& Novak, N. Histamine and histamine intolerance. Am J Clin Nutr 85, 1185-1196, https://doi.org/10.1093/ajcn/85.5.1185 (2007).

40. Valsamaki, K., Michaelidou, A. \& Polychroniadou, A. Biogenic amine production in feta cheese. Food Chemistry 71, 259-266, https://doi.org/10.1016/S0308-8146(00)00168-0 (2000).

41. Guarcello, R. et al. A survey of the main technology, biochemical and microbiological features influencing the concentration of biogenic amines of twenty Apulian and Sicilian (Southern Italy) cheeses. Int Dairy J 43, 61-69, https://doi.org/10.1016/j. idairyj.2014.11.007 (2015).

42. Schornsteiner, E., Mann, E., Bereuter, O., Wagner, M. \& Schmitz-Esser, S. Cultivation-independent analysis of microbial communities on Austrian raw milk hard cheese rinds. Int J Food Microbiol 180, 88-97, https://doi.org/10.1016/j. ijfoodmicro.2014.04.010 (2014)

43. Lecocq, J. \& Gueguen, M. Effects of $\mathrm{pH}$ and sodium chloride on the interactions between Geotrichum candidum and Brevibacterium linens. J Dairy Sci 77, 2890-2899, https://doi.org/10.3168/jds.S0022-0302(94)77229-5 (1994).

44. Quigley, L. et al. The complex microbiota of raw milk. FEMS Microbiol Rev 37, 664-698, https://doi.org/10.1111/1574-6976.12030 (2013).

45. Schmitz-Esser, S. et al. Abundance and potential contribution of Gram-negative cheese rind bacteria from Austrian artisanal hard cheeses. Int J Food Microbiol 266, 95-103, https://doi.org/10.1016/j.ijfoodmicro.2017.11.013 (2018).

46. Chun, J. \& Rainey, F. A. Integrating genomics into the taxonomy and systematics of the Bacteria and Archaea. Int J Syst Evol Microbiol 64, 316-324, https://doi.org/10.1099/ijs.0.054171-0 (2014).

47. Stackebrandt, E. \& Ebers, J. Taxonomic parameters revisited: tarnished gold standards. Microbiology Today 33, 152-155 (2006).

48. Liu, M., Nauta, A., Francke, C. \& Siezen, R. J. Comparative genomics of enzymes in flavor-forming pathways from amino acids in lactic acid bacteria. Appl Environ Microbiol 74, 4590-4600, https://doi.org/10.1128/AEM.00150-08 (2008).

49. Dias, B. \& Weimer, B. Purification and characterization of L-methionine gamma-lyase from Brevibacterium linens BL2. Appl Environ Microbiol 64, 3327-3331 (1998).

50. Gordon, W. G., Semmett, W. F. \& Bender, M. Alanine, glycine and proline contents of casein and its components. J Am Chem Soc 72, 4282-4282, https://doi.org/10.1021/ja01165a514 (1950).

51. Mikulec, N., Habuš, I., Antunac, N., Vitale, L. \& Havranek, J. Free amino acid profile during ripening of ewe's milk cheese from the Croatian island Krk. Int J Dairy Technol 66, 390-395, https://doi.org/10.1111/1471-0307.12032 (2013).

52. Moller, K. K., Rattray, F. P., Bredie, W. L. P., Hoier, E. \& Ardo, Y. Physicochemical and sensory characterization of Cheddar cheese with variable $\mathrm{NaCl}$ levels and equal moisture content. J Dairy Sci 96, 1953-1971, https://doi.org/10.3168/jds.2012-5524 (2013).

53. Rattray, F. P., Bockelmann, W. \& Fox, P. F. Purification and characterization of an extracellular proteinase from Brevibacterium linens ATCC 9174. Appl Environ Microbiol 61, 3454-3456 (1995).

54. Rattray, F. P. \& Fox, P. F. Purification and characterisation of an intracellular aminopeptidase from Brevibacterium linens ATCC 9174. Le Lait 77, 169-180 (1997).

55. Fernández, J., Mohedano, A. F., Gaya, P., Medina, M. \& Nuñez, M. Purification and properties of two intracellular aminopeptidases produced by Brevibacterium linens SR3. Int Dairy J 10, 241-248, https://doi.org/10.1016/S0958-6946(00)00046-7 (2000).

56. Rattray, F. P., Fox, P. F. \& Healy, A. Specificity of an extracellular proteinase from Brevibacterium linens ATCC 9174 on bovine betacasein. Appl Environ Microbiol 63, 2468-2471 (1997).

57. Rijnen, L., Bonneau, S. \& Yvon, M. Genetic characterization of the major lactococcal aromatic aminotransferase and its involvement in conversion of amino acids to aroma compounds. Appl Environ Microbiol 65, 4873-4880 (1999).

58. Rattray, F. P. \& Fox, P. F. Purification and characterization of an intracellular esterase from Brevibacterium linens ATCC 9174. Int Dairy J 7, 273-278, https://doi.org/10.1016/S0958-6946(97)00013-7 (1997).

59. Gummalla, S. \& Broadbent, J. R. Tyrosine and phenylalanine catabolism by Lactobacillus cheese flavor adjuncts. J Dairy Sci 84, 1011-1019 (2001).

60. Helinck, S., Le Bars, D., Moreau, D. \& Yvon, M. Ability of thermophilic lactic acid bacteria to produce aroma compounds from amino acids. Appl Environm Microbiol 70, 3855-3861 (2004).

61. Moore, M., Svenson, C., Bowling, D. \& Glenn, D. Complete nucleotide sequence of a native plasmid from Brevibacterium linens. Plasmid 49, 160-168 (2003).

62. Leret, V., Trautwetter, A., Rince, A. \& Blanco, C. pBLA8, from Brevibacterium linens, belongs to a gram-positive subfamily of ColE2related plasmids. Microbiology 144(Pt 10), 2827-2836, https://doi.org/10.1099/00221287-144-10-2827 (1998).

63. Ankri, S., Bouvier, I., Reyes, O., Predali, F. \& Leblon, G. A. Brevibacterium linens pRBL1 replicon functional in Corynebacterium glutamicum. Plasmid 36, 36-41, https://doi.org/10.1006/plas.1996.0029 (1996).

64. Schyns, G. et al. Isolation and characterization of new thiamine-deregulated mutants of Bacillus subtilis. J Bacteriol 187, 8127-8136, https://doi.org/10.1128/JB.187.23.8127-8136.2005 (2005).

65. Rodriguez, G. M. \& Smith, I. Identification of an ABC transporter required for iron acquisition and virulence in Mycobacterium tuberculosis. J Bacteriol 188, 424-430, https://doi.org/10.1128/JB.188.2.424-430.2006 (2006).

66. Ryndak, M. B., Wang, S., Smith, I. \& Rodriguez, G. M. The Mycobacterium tuberculosis high-affinity iron importer, IrtA, contains an FAD-binding domain. J Bacteriol 192, 861-869, https://doi.org/10.1128/JB.00223-09 (2010).

67. Ramon-Garcia, S., Martin, C., De Rossi, E. \& Ainsa, J. A. Contribution of the Rv2333c efflux pump (the Stp protein) from Mycobacterium tuberculosis to intrinsic antibiotic resistance in Mycobacterium bovis BCG. J Antimicrob Chemother 59, 544-547, https://doi.org/10.1093/jac/dk1510 (2007).

68. Almeida, M. et al. Construction of a dairy microbial genome catalog opens new perspectives for the metagenomic analysis of dairy fermented products. BMC Genomics 15, 1101, https://doi.org/10.1186/1471-2164-15-1101 (2014).

69. Kato, F. et al. Isolation of plasmids from Brevibacterium. Agric Biol Chem 53, 879-881, https://doi.org/10.1080/00021369.1989.1086 9391 (1989).

70. Sandoval, H., del Real, G., Mateos, L. M., Aguilar, A. \& Martín, J. F. Screening of plasmids in non-pathogenic corynebacteria. FEMS Microbiol Lett 27, 93-98, https://doi.org/10.1111/j.1574-6968.1985.tb01645.x (1985).

71. Dib, J. R. et al. Complete genome sequence of pAP13, a large linear plasmid of a Brevibacterium strain isolated from a saline lake at 4,200 meters above sea level in Argentina. Genome Announc 1, https://doi.org/10.1128/genomeA.00878-13 (2013).

72. Dib, J. R., Wagenknecht, M., Hill, R. T., Farias, M. E. \& Meinhardt, F. Novel linear megaplasmid from Brevibacterium sp isolated from extreme environment. J Basic Microbiol 50, 280-284, https://doi.org/10.1002/jobm.200900332 (2010).

73. Nardi, M. et al. Genetic transformation of Brevibacterium linens strains producing high amounts of diverse sulphur compounds. J Dairy Res 72, 179-187 (2005).

74. Valdes-Stauber, N. \& Scherer, S. Isolation and characterization of Linocin M18, a bacteriocin produced by Brevibacterium linens. Appl Environ Microbiol 60, 3809-3814 (1994).

75. de la Torre, M. et al. Histamine catabolism in Pseudomonas putida U: identification of the genes, catabolic enzymes and regulators. Environ Microbiol 20, 1828-1841, https://doi.org/10.1111/1462-2920.14118 (2018). 
76. Choi, Y. H. et al. Copper/topa quinone-containing histamine oxidase from Arthrobacter globiformis. Molecular cloning and sequencing, overproduction of precursor enzyme, and generation of topa quinone cofactor. J Biol Chem 270, 4712-4720 (1995).

77. Leuschner, R. G. \& Hammes, W. P. Degradation of histamine and tyramine by Brevibacterium linens during surface ripening of Munster cheese. J Food Prot 61, 874-878 (1998).

78. Leuschner, R. G., Heidel, M. \& Hammes, W. P. Histamine and tyramine degradation by food fermenting microorganisms. Int $J$ Food Microbiol 39, 1-10 (1998)

79. Coton, M. et al. Diversity and assessment of potential risk factors of Gram-negative isolates associated with French cheeses. Food Microbiol 29, 88-98, https://doi.org/10.1016/j.fm.2011.08.020 (2012).

80. Bankevich, A. et al. SPAdes: a new genome assembly algorithm and its applications to single-cell sequencing. J Computat. Biol 19, 455-477, https://doi.org/10.1089/cmb.2012.0021 (2012).

81. Wattam, A. R. et al. Improvements to PATRIC, the all-bacterial bioinformatics database and analysis resource center. Nucleic Acids Res 45, D535-D542, https://doi.org/10.1093/nar/gkw1017 (2017).

82. UniProt Consortium, T. UniProt: the universal protein knowledgebase. Nucleic Acids Res 46, 2699, https://doi.org/10.1093/nar/ gky092 (2018).

83. Finn, R. D. et al. The Pfam protein families database: towards a more sustainable future. Nucleic Acids Res 44, D279-285, https://doi. org/10.1093/nar/gkv1344 (2016).

84. Richter, M., Rosselló-Móra, R., Oliver Glöckner, F. \& Peplies, J. JSpeciesWS: a web server for prokaryotic species circumscription based on pairwise genome comparison. Bioinformatics 32, 929-931, https://doi.org/10.1093/bioinformatics/btv681 (2016).

85. Kumar, S., Stecher, G. \& Tamura, K. MEGA7: molecular evolutionary genetics analysis version 7.0 for bigger datasets. Mol Biol Evol 33, 1870-1874, https://doi.org/10.1093/molbev/msw054 (2016).

86. Bustin, S. A. et al. The MIQE guidelines: minimum information for publication of quantitative real-time PCR experiments. Clin Chem 55, 611-622, https://doi.org/10.1373/clinchem.2008.112797 (2009).

87. Mimura, H. Growth enhancement of the halotolerant Brevibacterium sp. JCM 6894 by methionine externally added to a chemically defined medium. Biocontrol Sci 19, 151-155, https://doi.org/10.4265/bio.19.151 (2014).

88. de Melo, A. G. et al. Complete genome sequence of Brevibacterium linens SMQ-1335. Genome Announc 4, https://doi.org/10.1128/ genomeA.01242-16 (2016).

\section{Acknowledgements}

We thank Eva Nischler for the help with isolating cheese rind bacteria and assisting with qPCR. We would also like to thank Elisa Schornsteiner for her help during sampling and processing of the samples. Othmar Bereuter is greatly acknowledged for facilitating the sampling at the cheese production plants. The research was funded by the Landwirtschaftskammer Vorarlberg, Austria. The funders had no role in study design, data collection and analysis, decision to publish, or preparation of the manuscript. Martin Wagner's work was partly financed by the Austrian Competence Center for Feed and Food Quality, Safety and Innovation (FFoQSI).

\section{Author Contributions}

J.M.A., M.D., D.L.S., E.M., S.S.E.: Performed experimental work and genome analyses. J.M.A., M.W., M.D., E.M., S.S.E.: Wrote the manuscript. S.S.E., E.M., M.W.: Conceived and designed the experiments and data analysis procedures. All authors read and approved the final manuscript.

\section{Additional Information}

Supplementary information accompanies this paper at https://doi.org/10.1038/s41598-019-42525-y.

Competing Interests: The authors declare no competing interests.

Publisher's note: Springer Nature remains neutral with regard to jurisdictional claims in published maps and institutional affiliations.

Open Access This article is licensed under a Creative Commons Attribution 4.0 International License, which permits use, sharing, adaptation, distribution and reproduction in any medium or format, as long as you give appropriate credit to the original author(s) and the source, provide a link to the Creative Commons license, and indicate if changes were made. The images or other third party material in this article are included in the article's Creative Commons license, unless indicated otherwise in a credit line to the material. If material is not included in the article's Creative Commons license and your intended use is not permitted by statutory regulation or exceeds the permitted use, you will need to obtain permission directly from the copyright holder. To view a copy of this license, visit http://creativecommons.org/licenses/by/4.0/.

(C) The Author(s) 2019 